\title{
Prilog II. \\ “Desničini susreti 2010.”: Ideologija vlasti i ideologičnost teksta
}

\section{Program rada}

“Desničini susreti 2010." sastoje se od dva radna dijela - u Zadru, 17. i 18. rujna te u Islamu Grčkom, 19. rujna 2010. Tema ovogodišnjih zadarskih rasprava Ideologija vlasti i ideologičnost teksta slijedi temeljnu programsku orijentaciju "Desničinih susreta" s težišstem na kritičkoj refleksiji fenomena kulture i kulturalnosti s komparatističkog stajališta. Cilj ostaje isti, t.j., istraživanjima i stručnim raspravama propitati proturječne i često konfliktne fenomene i procese u hrvatskom i širem južnoslavenskom transkulturacijskom prostoru u modernom i postmodernom razdoblju (18.21. stoljeće).

U doba kad je živio i pisao Vladan Desnica nastalo je u nas i u svijetu mnoštvo pripovijesti i romana intelektualističke naravi, u kojima pripovjedač i/ili likovi formuliraju teoretske, svjetonazorske i filozofične iskaze, a silnice djelatne u zapletu i raspletu premještaju se iz polja erosa i moći (fizičke, materijalne, političke) u kognitivnu i intelektualnu sferu. Shvaćanja prirodnoga i povijesnoga svijeta, društva i čovjeka koja se mogu iščitati iz takve proze obično se dodiruju s nekim od suvremenih filozofija i teorija (na primjer, s filozofijom života, marksizmom, psihoanalizom, fenomenologijom, egzistencijalizmom), a u nekakvu su odnosu - afirmativnu ili polemičnu - i prema ideologiji vladajuće elite, što i njih same čini implicitno ideologičnima. Njihova je ideologičnost osobito zanimljiva ako su formulirani u ambijentima gdje je u političkom životu dominiralo ideološko jednoumlje. Jednoumna, autoritarna vlast ostavlja piscu neslobodu iskrene suradnje ili slobodu opasnoga nonkonformizma, ali i mogućnost da kao javna osoba podupire režim ili se o njemu ne izjašnjuje, a kao stvaralac inkodira u jezik književnosti ideologeme manje ili više strane ili prikriveno suprotstavljene režimskoj ideologiji.

U desetljećima kad je Desnica djelovao kao pisac nije u Hrvatskoj ni drugdje u Jugoslaviji manjkalo jednoumlja, ali je bilo i intelektualističke proze, koju su, osim niza njegovih novela i njegova romana Proljeća Ivana Galeba, obogatila i djela mnogih poznatih pisaca u svim južnoslavenskim sredinama. Naš skup želio bi ispitati u kojoj su mjeri svjetonazorski iskazi tadašnje naše pripovjedne književnosti, a prije svega Desničinih djela, bili pluralističniji od političkoga i medijskoga diskursa, kakva je bila njihova funkcija u danoj književnoj strukturi te koja su krupna pitanja - etička, estetička, društvena, politička, religijska, povijesnofilozofska - stvarala potrebu za ispravljanjem, nadmašivanjem ili negacijom vladajuće ideologije.

“Desničini susreti 2010.", kao i prethodni skupovi, imaju naglašeno istraživačku orijentaciju. Matična adresa "Desničinih susreta" je Centar za komparativnohistorijske i interkulturne studije Filozofskog fakulteta u Zagrebu, a u realizaciji partnerski sudjeluju ustanove navedene u naslovu ovog poziva.

Tema Ideologija vlasti i ideologičnost teksta također otvara nove mogućnosti pristupa Vladanu Desnici, njegovim iskustvima intelektualca, u rasponu od visokoga državnog činovnika do profesionalnog književnika, jednoga od najsmionijih u svome stvaralaštvu u to doba u nas.

Zadarski dio skupa realizira se u suradnji sa Sveučilištem u Zadru, a islamskogrčki u Kuli Stojana Jankovića. Pripremni odbor se najljepše zahvaljuje rektoru Sveučilišta u Zadru prof. dr. sc. Anti Uglešiću na gostoprimstvu, a njegovim suradnicima, posebno prorektoru prof. dr. sc. Vladimiru Skračiću, na pomoći u organizaciji održavanja skupa u Zadru. Najljepše se zahvaljujemo vlasnicima Kule Stojana Jankovića, inače, djeci pisca Vladana Desnice - gđi Olgi Škarić, dr. sc. Jeleni Ivićević Desnica, dr. sc. Nataši Desnica Žerjavić i dr. sc. Urošu Desnici - na gostoprimstvu u Kuli i svestranoj suradnji na revitalizaciji Kule, u čemu "Desničini susreti” imaju svoj istaknuti udio.

U Islamu Grčkom, u Kuli Stojana Jankovića, baštini obitelji Desnica, gdje je i Vladan Desnica stvorio velik dio svog opusa, pored dužnog iskazivanja pijeteta nad piščevim grobom u crkvici 


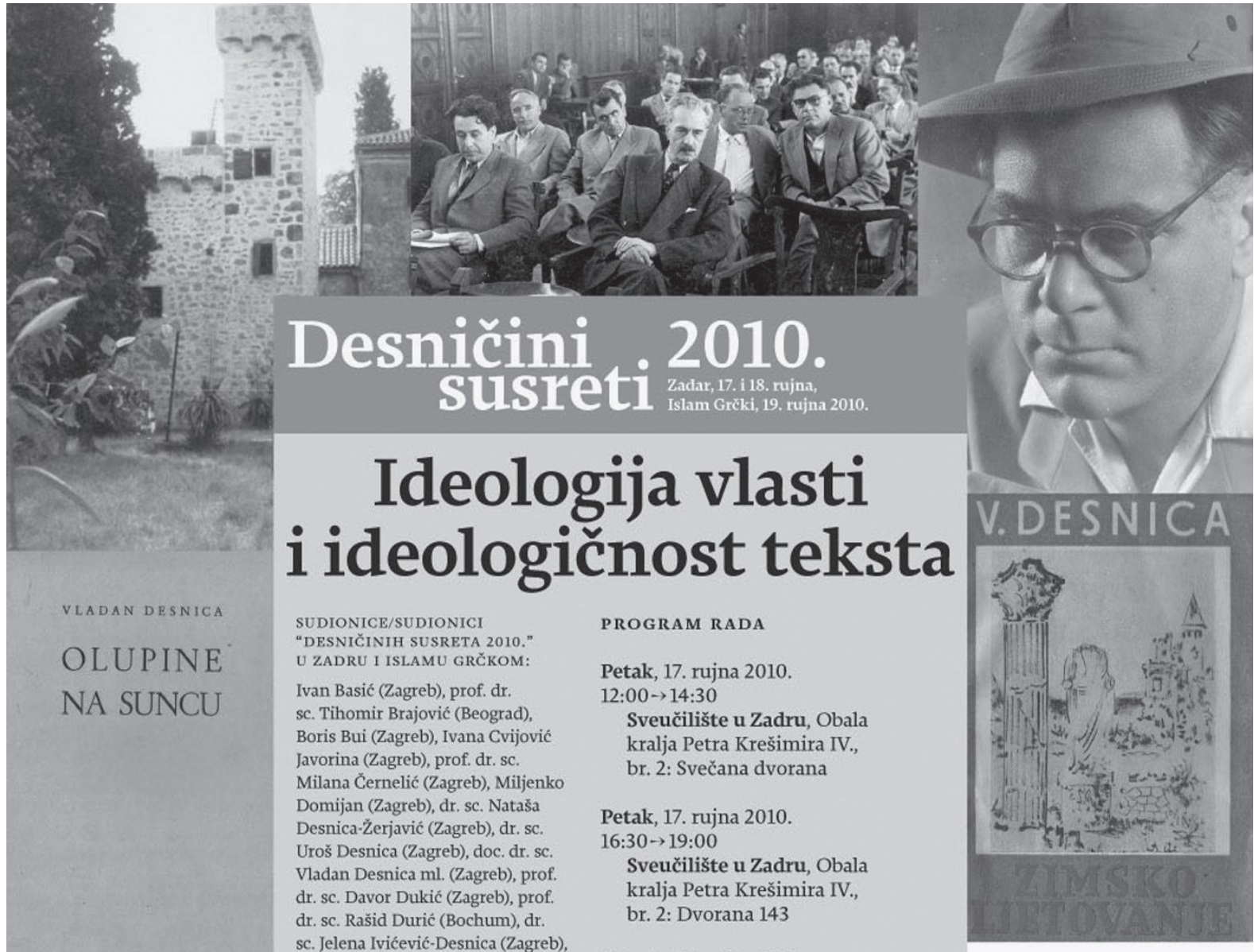

prof. dr. sc. Jadranka Grbić $\quad$ Subota, 18. rujna 2010.

Jakopović (Zagreb), dr. sc. Renata $\quad 9: 30 \rightarrow 11: 30,12: 00 \rightarrow 14: 30$

Jambrešić Kirin (Zagreb), Dževad Sveučilište u Zadru, Obala

Karahasan (Graz), Maša Kolanović ～kralja Petra Krešimira IV.,

(Zagreb), prof. dr. sc. Krištof Jacek

Kozak (Koper - Ljubljana), prof.

dr. sc. Zoran Kravar Zagreb), prof.

dr. sc. Dušan Marinković (Zagreb),

Lana Molvarec (Zagreb), mr. sc.

Magdalena Najbar-Agičić (Zagreb),

Mihajlo Pantić (Beograd), prof. dr.

sc. Helena Peričić (Zadar), prof.

dr. sc. Igor Radeka (Zadar), dr. sc.

Marijeta Rajković Iveta (Zagreb),

Ilija Ranić (Zagreb), prof. dr. sc.

Drago Roksandić (Zagreb), Olga

Škarić (Zagreb), dr. sc. Tatjana

Škarić-Jurić (Zagreb), Goranka

Šutalo (Zagreb), prof. dr. sc. Gojko

Tešić (Beograd - Novi Sad), Luca

Vaglio (Rim), Velimir Visković

br. 2: Dvorana 143

Nedjelja, 19. rujna 2010

$10: 00 \rightarrow 14: 30$ sati

Kula Stojana Jankovića

u Islamu Grčkom

PRIPREMILI UTI PODUPRLE

Filozofski fakultet Sveucilista u Zagrebu .

Centar za komparativnohistorijske i interkultume studije

Desnicini susrett ' Odsjek za kroatistiku Pilozofskog

Takuteta Sreuclista z Zagrebu - Hratsko drustro pisca

Centar za mirovne studije, Zagreb . Documenta: Centar

za suočavanje s proslošcu, Zagreb - Drustvo za obnovu

revitalizaciju Kule Stojana Jankovića • Europska Unija,

Bruxelles - Project 'Old Castle, More New Bridges' - Gradsid

ured za obrazovanje, kulturu isport Grada Zagreba.

Ministarstvo kulture Republike Hrvatske · Sveuciliste u Zadr
Savjet za nacionalne manjine Vlade Republike Hrvatske (Zagreb).

"Čak i oni koji nemaju nikakve veze $\mathrm{s}$ umjetnošću i nikakve ljubavi za nju, morali bi biti zahvalni nebu što ona postoji. Jer je to jedino područje ljudske djelatnosti gdje je nemoguća laž: čim laž proviri, istim časom, automatski prestaje umjetnost. U pravoj umjetnosti uvijek, beziznimno, uprkos svemu vlada istina: tu čovjek govori istinu čak $i$ proti svojoj volji."

(Vladan Desnica, "Zapisi o umjetnosti", Knugovi, 1952.)

\section{$7 / 1 / 49$}

$\rightarrow$ ligud $\ll$

(sunt forcoije)

$$
\begin{aligned}
& \text { (Cosifuireus. Tuth: - } \\
& \text {.... Kav on 2eto atren kaia xilice }
\end{aligned}
$$

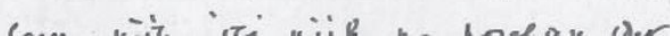


sv. Đurđa, prezentirat će se projekt Međunarodnoga sveučilišnog centra u Kuli Stojana Jankovića Sveučilišta u Zagrebu i Sveučilišta u Zadru te promovirati prva tri sveska Biblioteke "Desničini susreti”.

U nastavku programa 19. rujna 2010. godine, posjetit će se franjevački samostan u Karinu i srpskopravoslavni manastir Krupa u Bukovici te obići dijelovi Ravnih kotara i Bukovice u razgovoru s gosp. Miljenkom Domijanom, glavnim konzervatorom Ministarstva kulture Republike Hrvatske.

U programu "Desničinih susreta 2010." u nedjelju, 19. rujna 2010., koji se organizira u suradnji s Documenta. Centar za suočavanje s prošlošću iz Zagreba sudjelovat će poslijediplomski doktorski studenti upisani u kolegij "Oralna kultura i kultura sjećanja”, koji 2009/2010. godine zajednički realiziraju Vijeće Poslijediplomskoga doktorskog studija Odsjeka za povijest Filozofskog fakulteta u Zagrebu "Moderna i suvremena hrvatska povijest u europskom i svjetskom kontekstu", Documenta, Centar za ženske studije iz Zagreba i Centar za mirovne studije iz Zagreba. Zahvaljujemo gđi Vesni Teršelić na podršci i pomoći u organizaciji ovog dijela programa "Desničinih susreta 2010.”.

Podnositelji priopćenja iz Zagreba i oni koji će prethodno doći u Zagreb krenut će u Zadar u petak, 17. rujna 2010., točno u 8.00 ispred zgrade Hrvatskoga narodnog kazalita u Zagrebu.

\section{“Desničini susreti 2010.”: Ideologija vlasti $i$ ideologičnost teksta}

\section{Program rada}

Petak, 17. rujna 2010., s početkom u 12.00 sati

Otvaranje "Desničinih susreta 2009." od 12.00 do 12.30

(Sveučilište u Zadru, Obala kralja Petra Krešimira IV., br. 2: Svečana dvorana)

I. sjednica od 12.30 do 14.30

(Sveučilište u Zadru, Obala kralja Petra Krešimira IV., br. 2: Svečana dvorana)

Predsjedavaju: prof. dr. sc. Dušan Marinković i prof. dr. sc. Krištof Jacek Kozak

Zoran Kravar, prof. dr. sc. (Zagreb), Zimsko ljetovanje, roman i odjeci

Drago Roksandić, prof. dr. sc. (Zagreb), Civilna kultura Vladana Desnice poslije 1945. godine

Dževad Karahasan (Graz), Skeptični pripovjedač: okvir kao sredstvo ideologizacije i deideologizacije književnog djela

Tihomir Brajović, prof. dr. sc. (Beograd), Ironija i kolektivna memorija: Desnica, Krleža, Andrić

Od 14.30 do 16.30: Stanka za ručak

II. sjednica od 16.30 do 19.00

(Sveučilište u Zadru, Obala kralja Petra Krešimira IV., br. 2: Dvorana 143)

Predsjedavaju: prof. dr. sc. Davor Dukić i prof. dr. sc. Mihajlo Pantić

Miljenko Domijan (Zagreb), Baštinski identitet Zadra i još jedno čitanje Krležinog "Zlata i srebra Zadra" i Desničinog "O jednom gradu i jednoj zemlji" 
Gojko Tešić, prof. dr. sc. (Novi Sad i Beograd), ${ }_{1}^{1}$ Ideološki diskurs realizam/modernizam u srpskoj i hrvatskoj književnosti 1950-ih godina (posleratni modenristi i vlast)

Krištof Jacek Kozak, prof. dr. sc. (Koper i Ljubljana), Apsurdna tragika političke ideologije u slovenskoj dramatici

Renata Jambrešić Kirin, dr. sc. (Zagreb), “A odma’ te noćas može mrak odnijeti”: Književno stvaralaštvo kao svjedočenje između ideologizacije i estetitazije nasilja

Helena Peričić, prof. dr. sc. (Zadar), Jezik ideologije i ideologija jezika u Desničinoj drami Ljestve Jakovljeve

Subota, Zadar, 18. rujna 2010. godine

III. sjednica od 9.30 do 11.30

(Sveučilište u Zadru, Obala kralja Petra Krešimira IV., br. 2: Dvorana 143)

Predsjedavaju: prof. dr. sc. Gojko Tešić i Lana Molvarec

Davor Dukić, prof. dr. sc. i Goranka Šutalo (Zagreb), Todesenthebung aus dem Sterbebezimmer: Koncepti ideologije i vlasti u recepciji Desničinih Proljeća Ivana Galeba

Mihajlo Pantić, prof. dr. sc. (Beograd), Desničina priča o priči

Rašid Durić, prof. dr. sc. (Basel), Intelektualistička proza Vladana Desnice izmedu mimezisa i islamskog estetičkog iskustva

Luca Vaglio, dr. sc. (Rim), Vidovi policentraizma i problemiatičnosti u romanu Zimsko ljetovanje Vladana Desnice

Stanka za kavu od 11.30 do 12.00

IV. sjednica od 12.00 do 14.30

(Sveučilište u Zadru, Obala kralja Petra Krešimira IV., br. 2: Dvorana 143)

Predsjedava: Dževad Karahasan i prof. dr. sc. Helena Peričić

Lana Molvarec (Zagreb), Ideologija i epistemologija u Desničinim novelama

Igor Radeka, prof. dr. sc. (Zadar), Pedagogija i ideologija u Hrvatskoj: studij jednog slućaja

Maša Kolanović (Zagreb), ${ }^{2}$ Jedan roman i omladina na putu bratstva: poetika otpora Čangija Alojza Majetića

Dušan Marinković, prof. dr. sc. (Zagreb), Intervjui Vladana Desnice

Završna rasprava

Predsjedavaju prof. dr. sc. Zoran Kravar i prof. dr. sc. Drago Roksandić

Stanka za ručak od 14.30 do 16.30

Slobodno poslijepodne/obilazak Zadra

1 Prof. dr. sc. Gojko Tešić je bio spriječen sudjelovati u radu “Desničinih susreta 2010.” (nap. ur.).

2 Kolegica Maša Kolanović je bila spriječena osobno sudjelovati u radu skupa, ali je njezino unaprijed pripremljeno priopćenje bilo pročitano sudionicama/sudionicima (nap. ur.). 
Nedjelja, 19. rujna 2010., s početkom u 10.00 sati

\section{Kula Stojana Jankovića u Islamu Grčkom}

10.00.-10.30:

Dr. sc. Uroš Desnica - dobrodošlica u ime vlasnika Kule i

prof. dr. sc. Drago Roksandić - riječ zahvale u ime sudionica/sudionika "Desničinih susreta 2010.”

\section{Coctail}

10.30-10.45

Odavanje pošte Vladanu Desnici nad njegovim grobom u obiteljskoj crkvi sv. Đorđa (prof. dr. sc. Zoran Kravar i prof. dr. sc. Mihajlo Pantić)

10.45-11.45

\section{Kula Stojana Jankovića u Islamu Grčkom}

Prezentacija tri knjižna izdanja Biblioteke "Desničini susreti" Centra za komparativnohistorijske i interkulturne studije Filozofskog fakulteta Sveucilišta u Zagrebu:

Ivan Basić, Od domus episcopi do Kule Jankovića. Prostorni razvoj Kule Stojana Jankovića u Islamu Grčkom, FF press, Zagreb 2010.

Milana Černelić, Marijeta Rajković Iveta (uredile), Zapisi iz gornjih Ravnih kotara. Etnološki, povijesni i muzeološki prilozi o Islamu Latinskom, Islamu Grčkom, Kašiću I Podgradini, FF press, Zagreb 2010.

Drago Roksandić, Ivana Cvijović (uredili), Zbornik radova “Desničini susreti 2005. - 2008.", Plejada, Zagreb 2010.

Predstavljači izdanja (abecednim redoslijedom):

- Ivan Basić, Odsjek za povijest umjetnosti Filozofskog fakulteta u Zagrebu

- Boris Bui, urednik, FF press, Filozofski fakultet u Zagrebu

- Ivana Cvijović Javorina, suurednica Zbornika "Desničini susreti 2005. - 2008., studentica poslijediplomskog doktorskog studija, Odsjek za povijest Filozofskog fakulteta u Zagrebu

- Milana Černelić, prof. dr. sc., Odsjek za etnologiju i kulturnu antropologiju Filozofskog fakulteta u Zagrebu

- Jadranka Grbić Jakopović, prof. dr. sc., Odsjek za etnologiju i kulturnu antropologiju Filozofskog fakulteta u Zagrebu

- Marijeta Rajković Iveta, dr. sc., Odsjek za etnologiju i kulturnu antropologiju Filozofskog fakulteta u Zagrebu

- Ilija Ranić, glavni urednik, Plejada d.o.o., Zagreb

- Drago Roksandić, prof. dr. sc., Odsjek za povijest Filozofskog fakulteta u Zagrebu

- Velimir Visković, predsjednik, Hrvatsko društvo pisaca, Zagreb

$11.45-12.45$

Upoznavanje s Kulom i njezinim neposrednim okolišom te posebno s dijelom prostora dogovorenog za projekt Međunarodnoga sveučilišnog centra Sveučilišta u Zagrebu i Sveučilišta u Zadru 
Nakon završenog programa u Islamu Grčkom sudionici će ići posjetiti:

Karin te posebno franjevački samostan u Karinu,

Obrovac (posebno, kuća obitelji Desnica, pretpostavljeni izvorni ambijent Proljeća Ivana Galeba), Zaton Obrovački (ručak u restaurantu "Anita"),

Kaštel Žegarski i na kraju posjet srpskopravoslavnom manastiru Krupa u Bukovici, nedaleko Obrovca na putu za Zagreb.

Stručne obavijesti i rasprava o mogućnostima revitalizacije regionalne baštine:

gosp. Miljenko Domijan, glavni konzervator u Ministarstvu kulture Republike Hrvatske

Povratak u Zagreb je realno očekivati između 19 i 20 sati. 